\title{
Older People, Sense of Coherence and Community
}

\author{
Maria Koelen and Monica Eriksson
}

\section{Introduction}

Population ageing is a global trend. For example, in the EU-27 population, the share of the older population (65 and above) increased from $13.9 \%$ in 1991 to $19.7 \%$ in 2018 (Eurostat, 2018). It is expected that by 2060, the share of those 65 years and over will account for $29.5 \%$ of the EU-27 population (Eurostat, 2013). Moreover, we can observe a worldwide increase in very old people, aged 85 and over. The ageing of the population results from decreasing fertility rates, but also from increasing life expectancy rates and the progressive ageing of the ageing population itself. These latter trends are partially attributable to improved quality of nutrition, and advances in medicine, especially knowledge about diseases and their control, and to developments such as early detection of colorectal and breast cancer in screening programmes which increase the chances of survival. Improvements in housing, nutrition and sanitation standards have also contributed to improved life expectancy (Staehelin, 2005).

In middle- and high-income countries, years added to life are generally lived in good health. However, because more people live into old age and because chronic diseases - such as cancers, diabetes, heart disease, Alzheimer disease and related dementias - more frequently occur in the older population, the burden of disease will also increase. The ageing of the population will have an impact on health care,

This chapter is a revision and update of work published in Mittelmark, M.B., Sagy, S., Eriksson, M., Bauer, G., Pelikan, J.M., Lindström, B., \& Espnes, G.A. (eds). (2017). The Handbook of Salutogenesis. Springer, Cham. DOI: https://doi.org/10.1007/978-3-319-04600-6

M. Koelen $(\triangle)$

Department of Social Sciences, Health and Society Group,

Wageningen University, Wageningen, The Netherlands

e-mail: koelen@caiway.nl

M. Eriksson

Department of Health Sciences, University West,

Trollhättan, Sweden housing and community facilities, consumption patterns and also on social security costs. In response, health professionals, researchers and policymakers are increasingly concerned with healthy ageing, where ageing in place is used as a key concept. In this chapter, we first discuss the meaning of the concept of healthy ageing, and how sense of coherence contributes to this process. Next, we discuss the characteristics of the community in which older people live their lives and how the community can contribute to healthy ageing in place.

\section{From Healthy Ageing to Salutogenic Ageing}

The simple question, 'when is someone old?' is not easily answered. Up to now, the question is mainly answered from an exogenous, administrative and political perspective (Koelen, 2011). In many countries, 'becoming old' is defined by retirement (in countries where retirement exists) or chronological age (Cattan, 2009). Retirement age can however vary, from 55 to 75 years of age, depending on country and/ or profession. Occasionally, people of ages 45 or 50 years are included under the label 'older' for policy or research purposes. At the same time, several countries seek to increase the paid work participation and to increase state-pensionage. Hence, defining 'old age' simply as chronological age can be rather misleading, particularly if we accept the social construct of old age. It is not possible, in this chapter, to explore the extensive debates, theories and research paradigms linked to ageing and old age, but suffice to say that the concept will continue to be redefined and refined as our perceptions and understanding of old age evolve. This is also true for the concept of healthy ageing. There are many definitions for 'healthy ageing', and the concept is often used alongside related concepts such as 'effective ageing', 'positive ageing', 'successful ageing' and 'ageing well'. HansonKyle (2005, p. 52) summarized different definitions and, based on commonalities, defines healthy ageing as 'the process of slowing down, physically and cognitively, while 
resiliently adapting and compensating in order to optimally function and participate in all areas of one's life (physical, cognitive, social and spiritual)'. The World Health Organization previously proposed to use the concept of 'active ageing', defined as 'the process of optimizing opportunities for health, participation and security in order to enhance quality of life as people age' (WHO, 2002; p. 12). In their 2015 World Report on Ageing and Health, WHO replaced the concept of active ageing by healthy ageing, defined as 'the process of developing and maintaining the functional ability that enables wellbeing in older age'. Functional ability is about having the capabilities that enable people to be and do what they have reason to value. It is made up of the intrinsic capacity of the individual, relevant environmental characteristic and the interaction between them (WHO, 2015). Intrinsic capacity is defined as the composite of all the physical and mental (including psychosocial) capacities that an individual can draw on at any point in time (Beard et al., 2016; Sadana and Michel, 2019).

The meaning attached to healthy ageing also depends on whether it is defined by professionals or by older people. Research reveals that older people have a different view from that of professionals, research scientists and policymakers. Older people may report that they experience good health and well-being, regardless of their clinical condition, impairment or disability (Young et al., 2009; Sadana and Michel, 2019). Professionals frequently focus on negatively phrased topics such as disability, disease, loneliness, overweight and falls, thereby emphasizing the problems and limitations that occur due to ageing. Older people focus more on supportive social environments, the ability to use resources, the ability to manage restrictions (Naaldenberg et al., 2011), the ability to make one's own decisions (Stephens et al., 2015) and on adaptation, meaningfulness and connectedness (Jeste et al., 2010). This perception relates to the increasingly accepted definition of health as 'the ability to adapt and self-manage' (Huber et al., 2011). Kennaugh (2016) explored how older Australian women experienced ageing. Using a salutogenic approach to ageing the focus in her doctoral thesis in philosophy, 'It's not how old we are; it's how we are old', was to understand the main issues that were reported by older women to be important, how they coped as they aged and how they adjusted following changes to their marital status. The women used multiple resources for strengthening SOC, which in turn enabled women to feel their life as comprehensible, manageable and meaningful. Despite the challenges of ageing, they found ways to manage the circumstances of life, and reported that they were indeed ageing well. In a systematic review on health assets in older age ( $n=78,422$ from more than 13 different countries), Hornby-Turner et al. (2017) evaluated an extensive range of health assets, highlighting the evidence for factors that positively influence health in older age. They found that higher scores of self-rated health, psychological well-being and life satisfaction were associated with better health in older age. Social network and contact with family and friends and engagement in leisure and social activities were important support mechanisms.

\section{Life Course Perspective}

Healthy ageing is a lifelong process, and it evolves through the lifespan from (pre-)conception, infancy, adolescence and young adulthood into old age. Lifespan is usually understood as the duration of a person's life history from conception to the end life. Genetic endowment, exposures to health enhancing or deteriorating occurrences in the physical and social environment at any moment in time influence health development across the lifespan (cf. Kuh and Ben Shlomo, 2004; Westendorp and Kirkwood, 2007; Kuh, 2019).

Older people are often seen as passive and frail, even though in reality a substantial number are quite resilient and active in managing the challenges they face as part of the ageing process. It should be recognized that older people do not constitute a heterogeneous group. People in their 60s and 70 s are typically healthy and most continue to live independently. The dependency of those in their 80s and above is typically prone to increasing frailty and susceptibility to illness and disability (Stones and Gullifer, 2016, p. 450), but also the older old increasingly prefer to live independently. Indeed, individual diversity increases with age across the life course (Marcoen et al., 2007). Or, as Aldwin et al. (2006) put it, 'some individuals become severely disabled in midlife, whereas others are running marathons in their 70s and even 80s' (p. 85).

From a life course perspective, old age (65+) may be considered as the 'last season', or the third age, but reaching the age of 65 years is not the last transition. Increasingly, we also talk about 'the fourth age' or 'the oldest old', meaning people of ages 85 years and over. Life course in this context is taken to mean the social aspect of the lifespan which involves biological, social and psychological processes leading to planned or unplanned life transitions and/or events. Importantly, a life course approach recognizes that ageing experiences are influenced by factors relating to cohort effects (Hubley and Copeman, 2008; Phillipson and Baars, 2007). Some issues related to this are unique for later life; others are of greater relevance in later life.

With increasing age, many changes occur in the social environment, as a result of retirement (loss of role), death of a spouse, death of family members and friends and the onset of age-related sensory loss and mobility problems. It has sometimes been said that old age is an accumulation of losses forcing older people to adapt and adjust to constantly changing physical and social environments. For most part, 
older people demonstrate great ability to find a range of different strategies to deal with these changes. Over time, however, the available options become fewer as a result of declining resources and ability. This can have an impact on the older person's mental health and increase the risk of social isolation and loneliness (Dykstra, 2009). Research has shown that the availability of social contacts and the ability to engage in social interaction are important in maintaining healthy ageing and alleviating loneliness (Forte, 2009; Nyqvist et al., 2013). In adapting to changing circumstances, older people may use a range of 'tools' available to them to facilitate engagement. Results from a systematic review and meta-analysis suggest a significant relationship between the Internet use (through, for example, social media, email, Skype) and mental well-being in older people (Forsman and Nordmyr, 2015). Research on the facilitation of social participation and the stimulation of social interaction is ongoing, but there are still gaps in our knowledge and understanding of the processes involved. However, research in associated areas has shown that there is an accumulation of socioeconomic disadvantage with regard to disability over the life course, leading to morbidity and mortality inequalities in later life (Kingston et al., 2015) and also that high levels of physical capability is associated with mental well-being in older people (Cooper et al., 2014). Such findings suggest that investigations of the role of social interaction in maintaining health over the life course may need to consider the wider constructs of health in old age, including socioeconomic factors and physical capability.

\section{Sense of Coherence and Its Three Dimensions}

Sense of coherence (SOC) reflects a person's view of life and capacity to respond to stressful situations. It is a global orientation to view the life as structured, manageable and meaningful or coherent. It is a personal way of thinking, being and acting, with an inner trust, which leads people to identify, benefit, use and reuse the resources at their disposal (Antonovsky, 1987; Lindström and Eriksson, 2005; Eriksson, 2017). SOC consists of three elements: comprehensibility, manageability and meaningfulness. The original definition is as follows: 'a global orientation that expresses the extent to which one has a pervasive, enduring though dynamic feeling of confidence that: (1) the stimuli from one's internal and external environments in the course of living are structured, predictable, and explicable; (2) the resources are available to one to meet the demands posed by these stimuli; and (3) these demands are challenges, worthy of investment and engagement' (Antonovsky, 1987, p. 19).
Comprehensibility refers to the extent to which a person perceives the stimuli confronted with, deriving from the internal and external environments, as making sense as information that is ordered, consistent, structured and clear. The person scoring high on the sense of comprehensibility expects that stimuli they encounter in the future will be predictable, ordered and explicit. This is the cognitive component of the SOC. Manageability is the extent to which a person perceives that resources are at their disposal that are adequate to meet the demands posed by the stimuli that bombards them. 'At a person's disposal' refers to resources under the person's own control or to resources controlled by legitimate others. This is the instrumental/behavioural component of the SOC. Meaningfulness refers to the extent to which a person feels that life makes sense emotionally, that problems and demands are worth investing energy in, are worthy of commitment and engagement, seen as challenges rather than burdens. This is the motivational component of the SOC. The original name of the instrument to measure sense of coherence is the life orientation questionnaire'. The original SOC scales consist either of 29 items, or a shortened form of 13 items. There are also modified translations of the instrument with varying number of questions and scoring alternatives. Up to date it has been used in at least 51 different languages in at least 51 different countries around the world. For more details of the SOC questionnaire, see Chaps. 11 and 12 in this book.

\section{Development of the SOC in the Life Course.}

A person's SOC affects and is affected at each stage across the lifespan by the surrounding environment and people in the local environment. In the mid-1980s, Antonovsky wrote an article about the importance of the sense of coherence for mental health and related this to a life course perspective (Antonovsky, 1985). In a lecture he gave in Berkeley, he discussed the transition from adolescence to adulthood and ageing, and argued for the usefulness of the salutogenic perspective (Antonovsky, 1993). He positioned ageing persons in a context of a health continuum, the ease/dis-ease continuum, and argued that people are all constantly moving in this continuum. People, dependent on age, are in different positions in this continuum. In Antonovsky's words: 'I propose that all living human beings, at any point in time, are somewhere on a continuum between the two extreme poles. An elderly person with a thick medical folder is no less on the continuum than an active, hungry, screaming, and smiling infant or than a strapping adolescent. They are at different points on the continuum; the dynamic prognoses are different.'

Antonovsky considered ageing as a process of human development instead of just a biological and mental 
degradation of the body: 'Is it not possible that the 10 billion neurons in the human cortex can come up with some replacement for what has senesced? Whatever the case may be for the biological development of salutary factors till the very end of life ..., I can surely see the possibility of the growth of social-psychological salutary factors as one gets older' (Antonovsky, 1993). These thoughts can be related to Erikson's theory of human identity development and the need for full awareness of context, especially as one gets older (Erikson and Erikson, 1998).

According to Antonovsky (1987), the SOC is assumed to develop until the age of 30 years, to remain stable until retirement, and thereafter to decrease. However, this assumption has not been empirically supported in previous research. The SOC seems to be relatively stable over time, but not as stable as initially assumed (Eriksson and Lindström, 2011). Research findings show that the SOC develops over the entire lifespan; in other words, it increases with age (Wiesmann and Hannich, 2019; Lövheim et al., 2012; Feldt et al., 2007, 2011; Nilsson et al., 2010). Wiesmann and Hannich (2019) investigated the stability of SOC over a time span of four years in active older German individuals $(n=125)$ and long-term effects of this life orientation on three different indicators of positive ageing subjective well-being, psychological health and physical health. This is the first study to explore associations between gain in sense of coherence and future positive ageing. They found that SOC increased over four years, disclosing a small effect size. The baseline SOC had a substantial predictive value for future subjective well-being and psychological health, but not for physical health. Analyses showed that both the baseline SOC and gain in SOC predicted future subjective well-being and psychological health.

Findings from additional longitudinal research ( $n=19.629$, response rate $80.2 \%$ ) sheds light over how the development of the SOC from different age groups can be understood. Feldt et al. (2011) found that the strongest development (46-58\%) was amongst those participants whose SOC was strong at baseline. A class of strong SOC with a decreasing trend and that of a weak SOC with an increasing trend was also found. Nilsson et al. (2010) were able to demonstrate on a sample of Swedes, aged 18-85 years ( $n=43.598)$, that SOC increases with age in both men and women. In a longitudinal study amongst Japanese volunteers aged 65 and over, Murayama et al. (2014) investigated the effect of intergenerational programmes on the mental health amongst older adults. They found that the meaningfulness component of the SOC significantly increased for members of the intervention group at all terms, with no changes in the control group over time. Participation in the intergenerational programme was associated with a sense of manageability which was also significantly related to depressive mood.

\section{SOC Contributes to Ageing Well}

Research amongst older people shows, as during other periods of the life cycle, that a strong sense of coherence is related to good perceived health and quality of life (Tan et al., 2013; Eriksson and Lindström, 2005, 2006) and mediate the association between perceived stress and depression (Guo et al., 2018; Boeckxstaens et al., 2016). In the longitudinal Aichi Gerontological Evaluation Study (AGES), the relationships between social factors and depression amongst older Japanese were investigated (Misawa and Kondo, 2019). They found that of the study participants without mental illness or depression at Wave 1, $14 \%$ had become depressed by Wave 2 (3-year follow-up). In both men and women, life events predicted increased odds of depression, whilst SOC predicted reduced odds. In a German study amongst older people ( $n=387$, mean age 73.8 years), the role that the SOC and generalized resistance resources have for older people's experience of life satisfaction was investigated (Dezutter et al., 2013; Wiesmann et al., 2014). The results showed that the SOC - as the ability to cope in everyday life - social support and self-esteem were factors that contributed to older people's satisfaction with life. In a population-based prospective cohort study in 29 primary care practices throughout Belgium ( $n=567$, ages $\geq 80$ ), subjects with strong SOC scores showed a higher cumulative survival than others ( $\log$ rank $=0.004)$ independent of other prognostic characteristics (adjusted hazard ratio $0.62(95 \%$ CI, 0.38-1.00). Even very elderly persons with strong SOC scores were shown to have lower mortality rates and less functional decline. These effects were independent of multimorbidity, depression, cognition, disability and sociodemographic characteristics (Boeckxstaens et al., 2016). A selection of studies using SOC amongst older people is shown in Table 19.1.

A Singaporean qualitative study amongst 27 older adults, using focus group interviews, was conducted and appreciative inquiry was adopted as a strengths-based interviewing approach (Seah et al., 2020). Four themes emerged: (1) contending evolving vulnerabilities, (2) intrinsic value of health, (3) taking care of oneself is a personal responsibility and (4) taking one day at a time: outlook towards later part of life (ibid, p. 3). The authors suggest that SOC towards the pursuit of healthy ageing can be addressed by reducing the unpredictability of ageing-related processes and vulnerabilities (comprehensibility), supporting active adoption of actions which promotes physical, mental and social health (manageability) and individual reflection in making sense of old age to seek motivation in living each day purposefully (meaningfulness). In another review study, Tan et al. (2013, p. 497) found that a strong SOC amongst older people was correlated with better physical, social and mental health. 


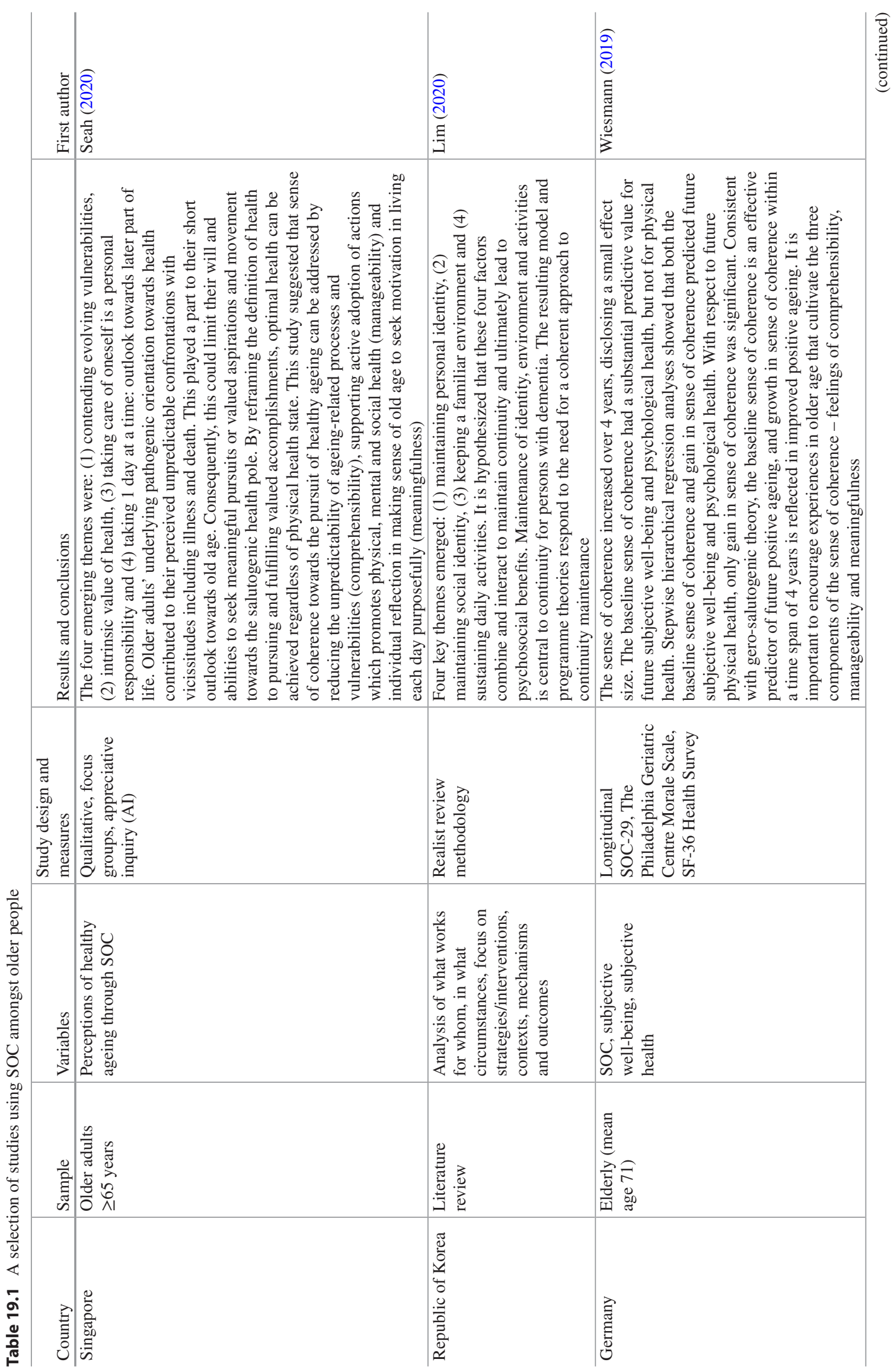




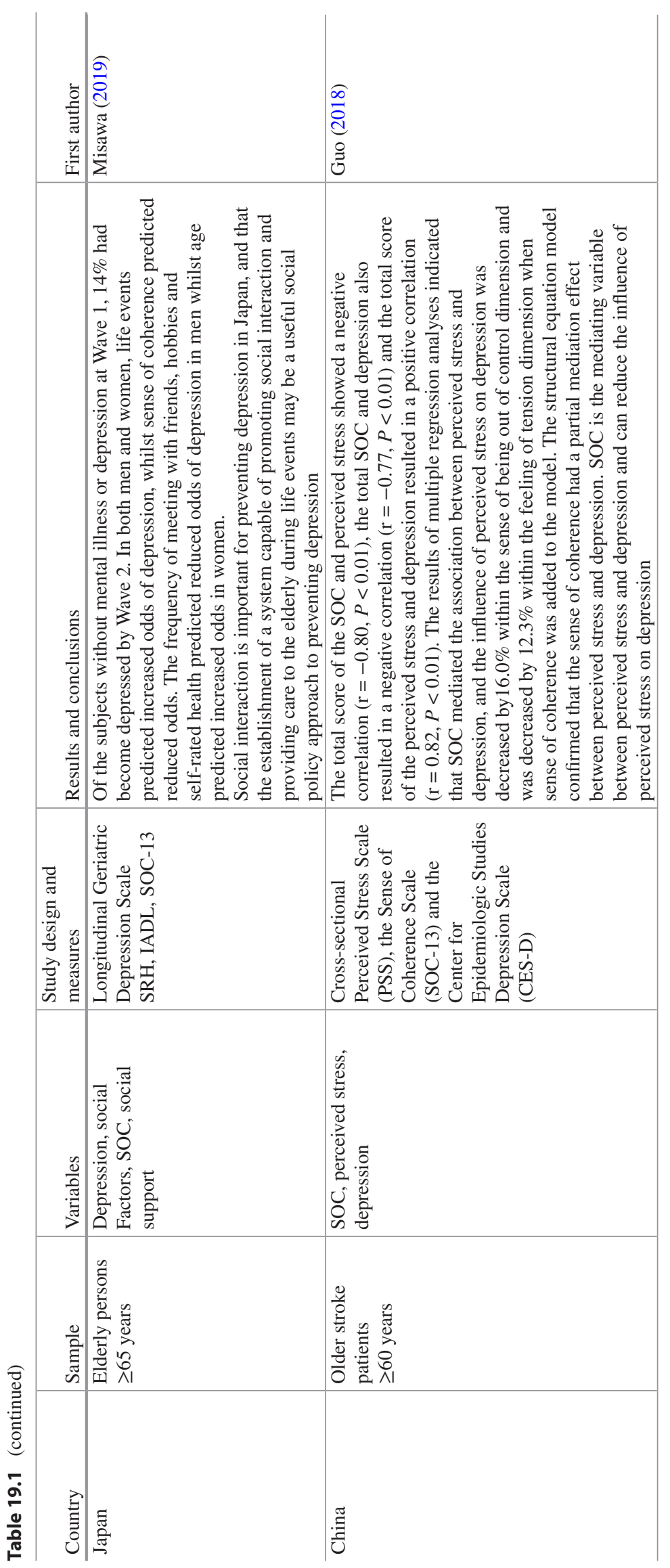




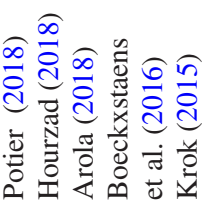

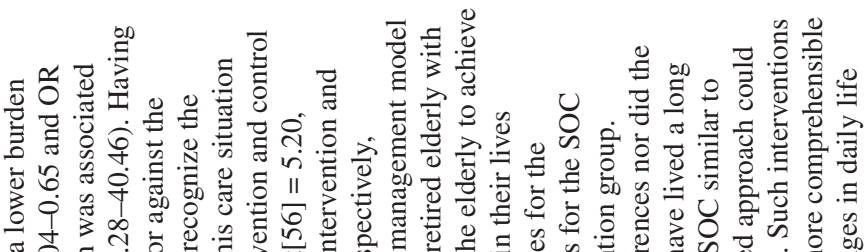

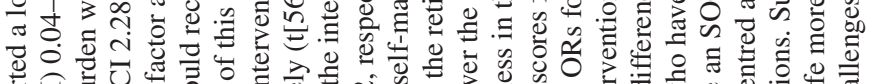

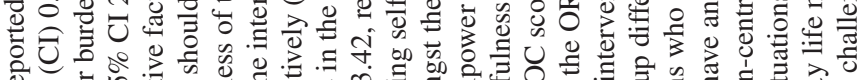

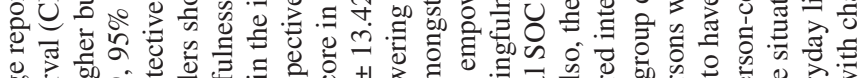

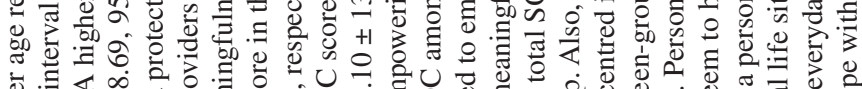

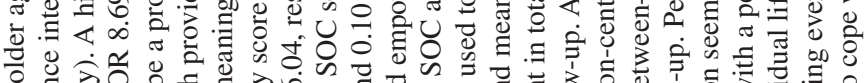

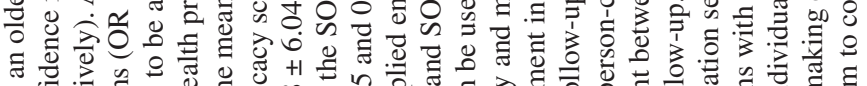

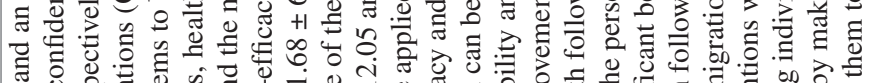

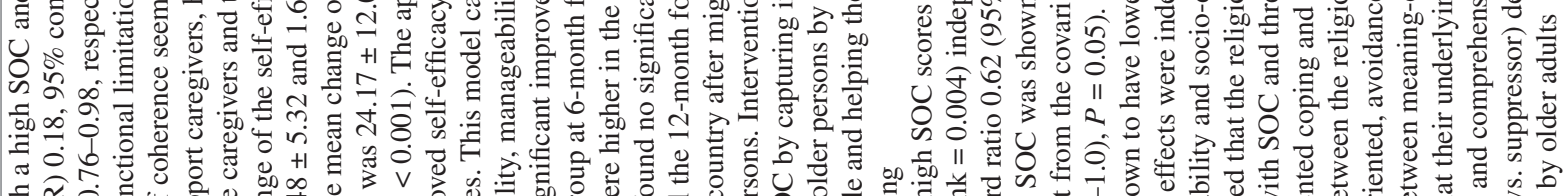

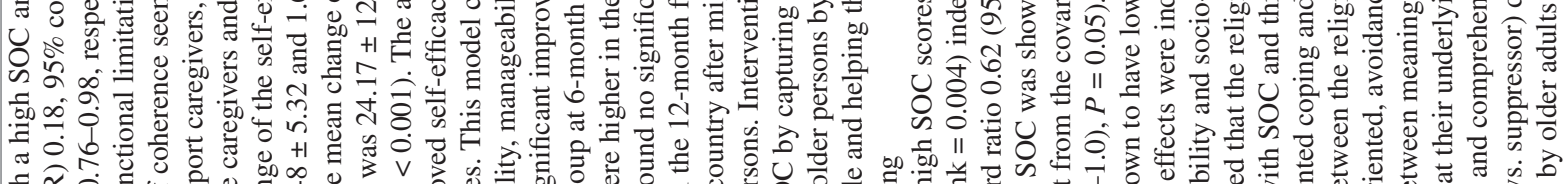

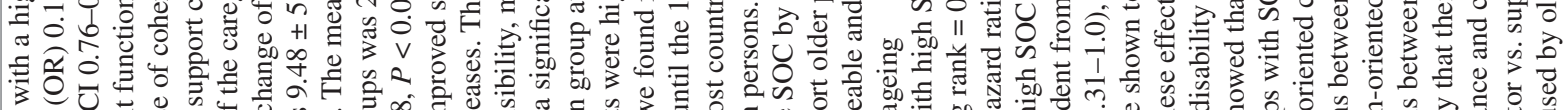

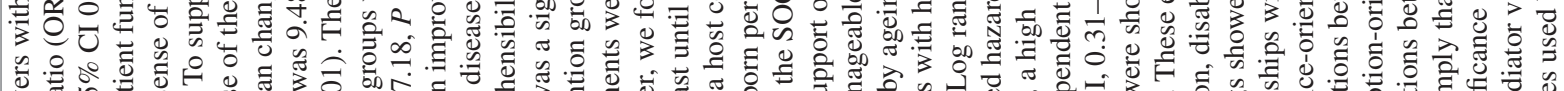

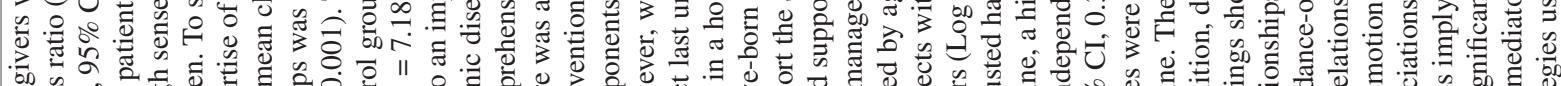

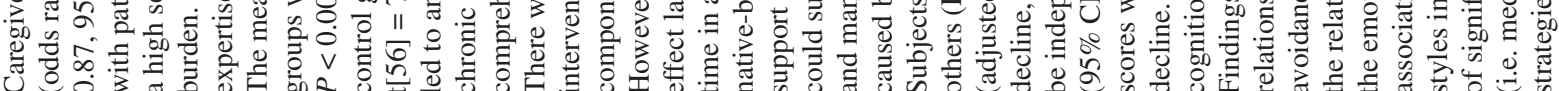

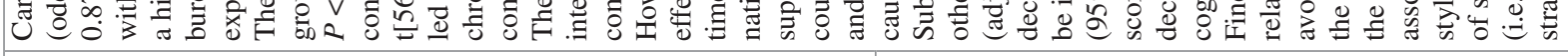

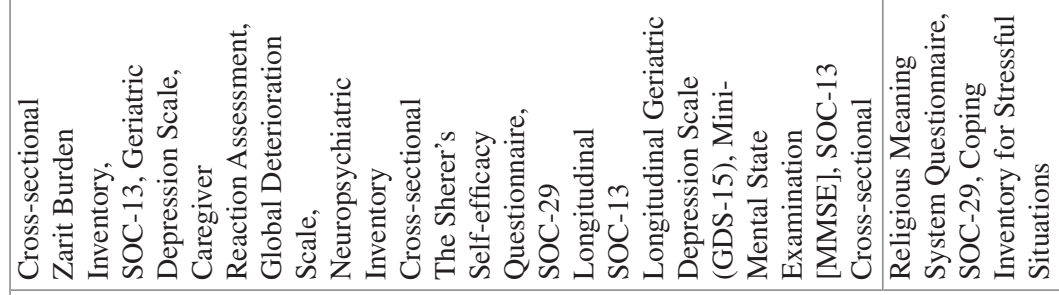

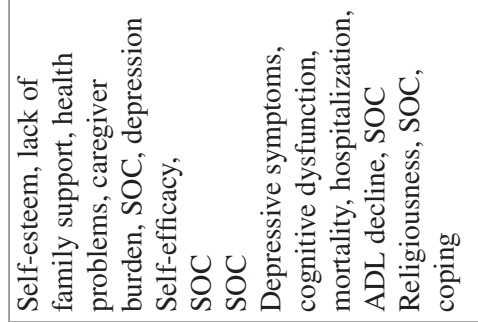

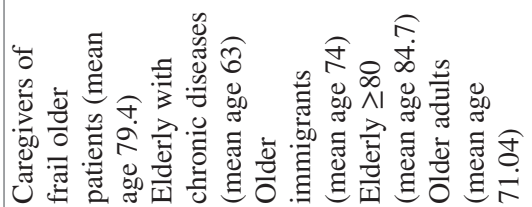

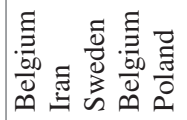




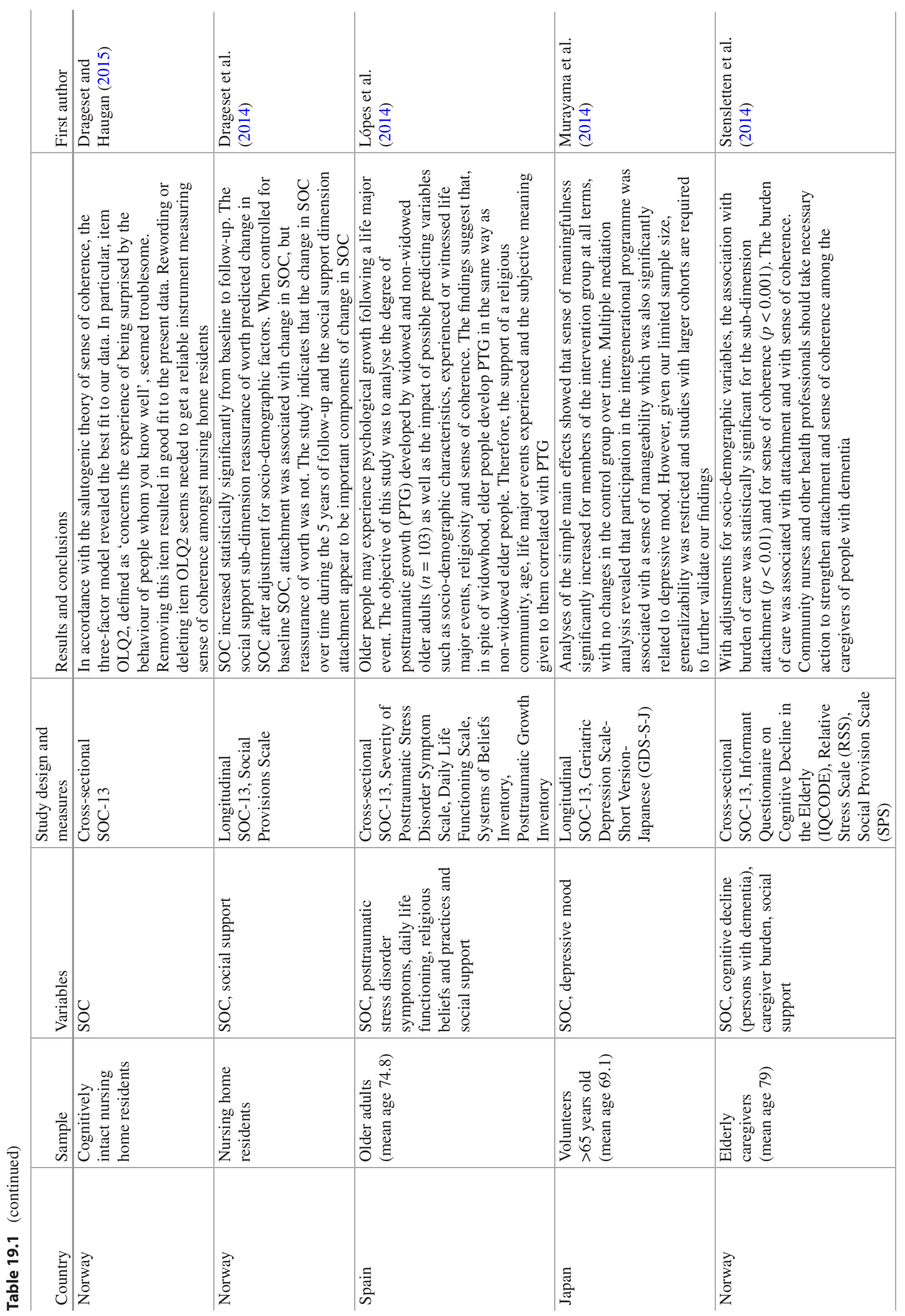




\begin{tabular}{|c|c|c|c|}
\hline 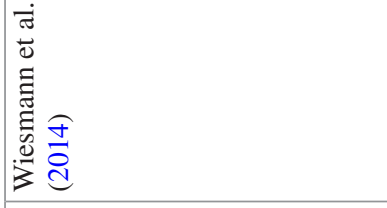 & 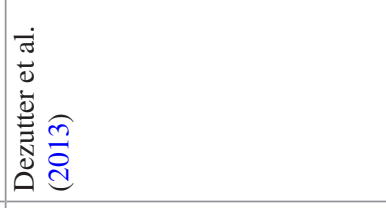 & 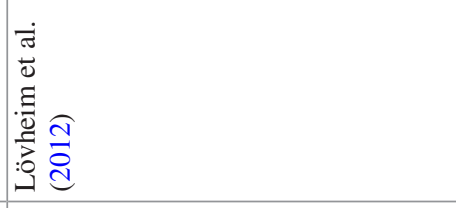 & 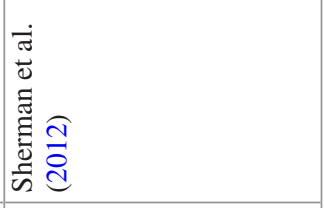 \\
\hline 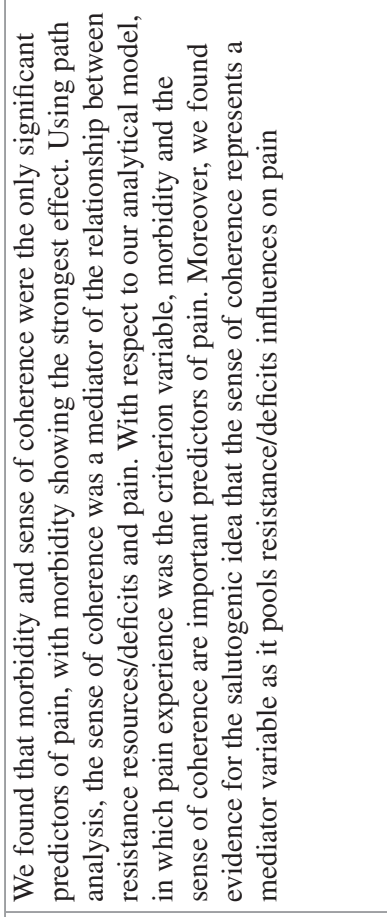 & 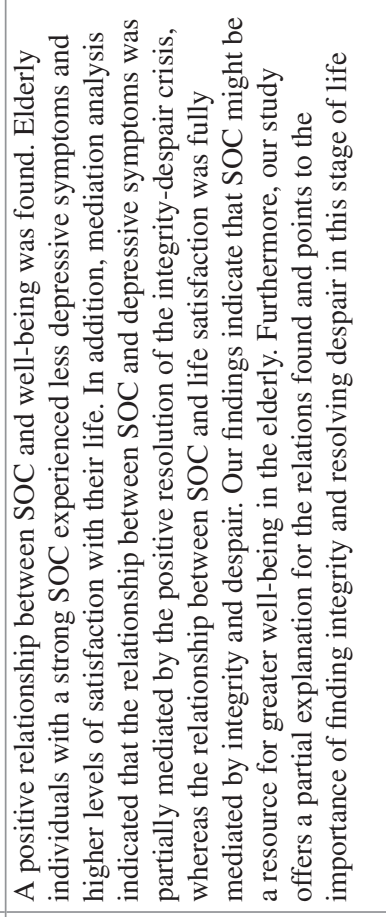 & 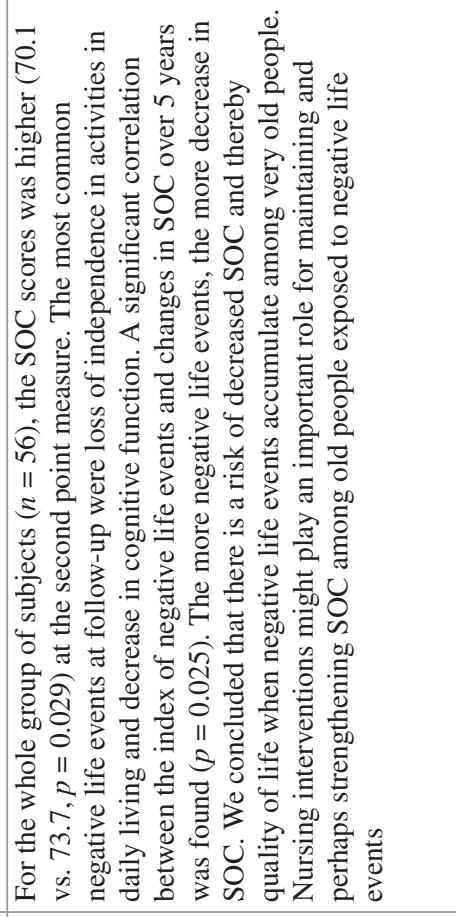 & 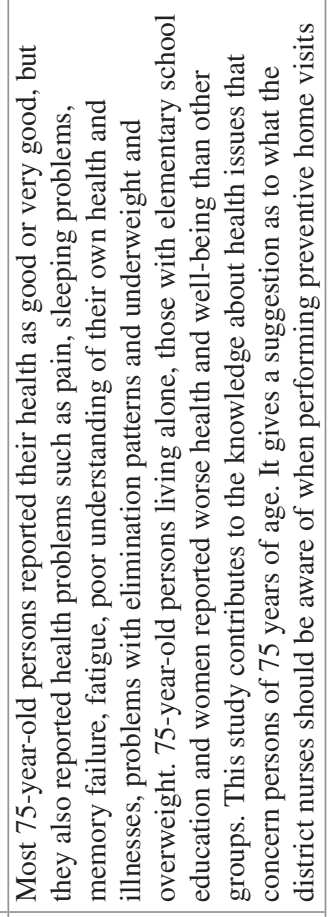 \\
\hline 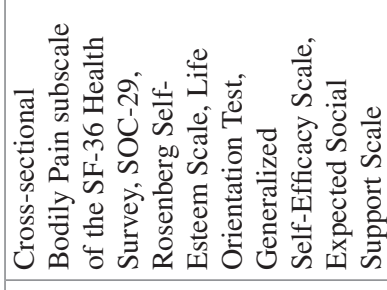 & 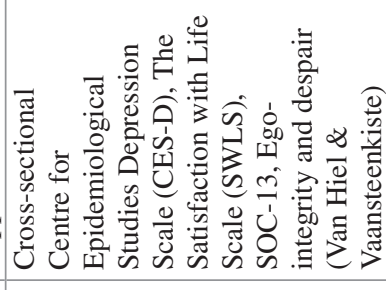 & 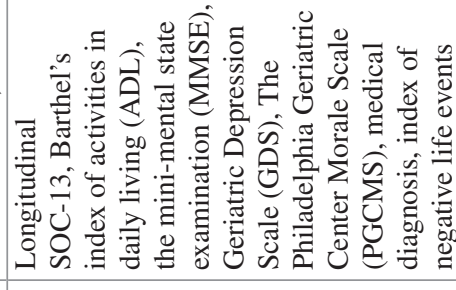 & 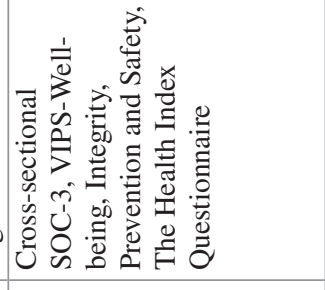 \\
\hline 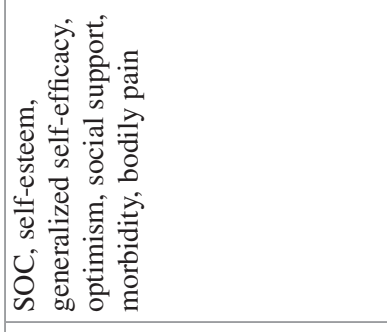 & 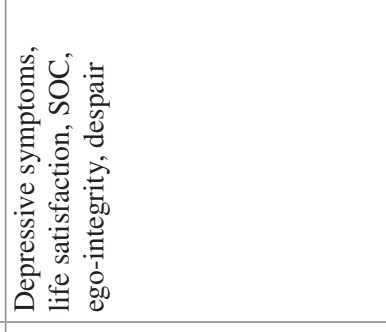 & 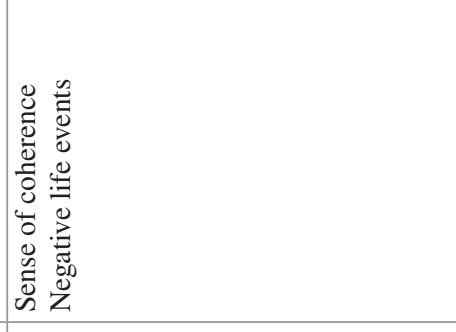 & 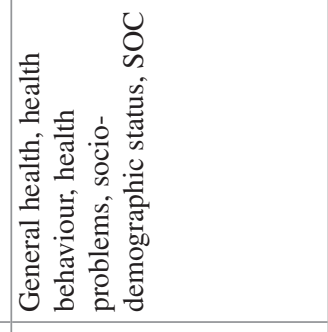 \\
\hline 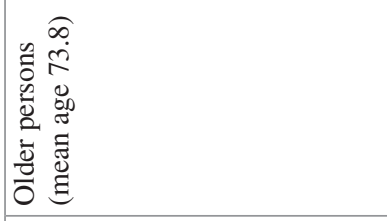 & 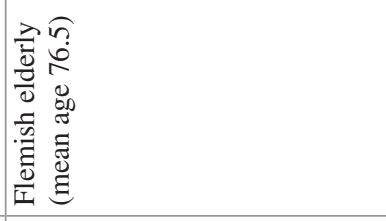 & 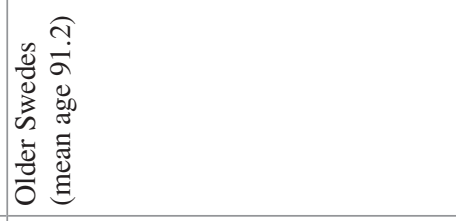 & 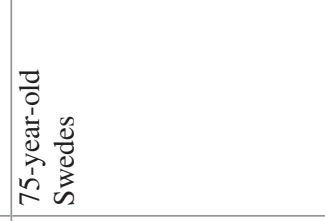 \\
\hline & & 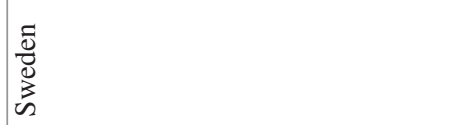 & 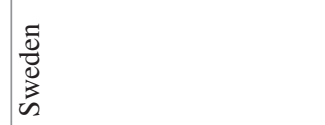 \\
\hline
\end{tabular}


Gender differences are reported in terms of SOC and perceived health amongst older people. In a Norwegian study amongst 242 older people (mean age 84.6 years), examining how the SOC affected the perception of health (Saevareid et al., 2007), it was found that both men and women had health problems directly related to perceived health, whilst psychological symptoms were directly related to perceived health only in men. The gender difference reduced the effect of SOC on perceived health.

As pointed out earlier, ageing is a process, and concepts such as successful ageing and healthy ageing are frequently used (Lezwijn et al., 2011). Salutogenic research also uses the term 'resilient ageing' (Hicks and Conner, 2014) and 'ageing well' (Kennaugh, 2016). As a basis for an EU conference 'Salutogenesis and the promotion of positive mental health in older people' (19-20 April 2010, Madrid, Spain), Billings and Hashem (2010) conducted a review of studies amongst older people using a salutogenic approach to ageing. The review included concepts and theories closely related to SOC, such as resilience, hardiness and religiosity (religious beliefs). The authors highlighted different models for healthy ageing, including factors such as self-reliance, sense of control over life and a positive attitude to life, all to be important determinants of good ageing. They also noted that although the salutogenic approach provides a valuable contribution to maintain and develop health amongst older people, research and application in practice had not achieved the expected attention and impact. In a qualitative study on Irish healthy and active older people, Walsh (2014) examined the salutogenic theory within the context of later life and considered the value of salutogenesis as an analytical perspective applicable to understanding older people's health and well-being as they age in place. The analysis and the results demonstrated the potential value of the qualitative application of the SOC and incorporate context and place as central positions of analysis. This method contributes to a deeper understanding of the health-place relationship.

For a long time, research on SOC has been focused on testing the validity and reliability of the SOC questionnaire in a variety of samples, for example, older people. Thus, we have a good knowledge of how a strong SOC mediates and moderates perceived stress in different samples (Guo et al., 2018; Potier, 2018; Eriksson and Lindström, 2005, 2006). A new trend in salutogenic research is emerging, that is the development of salutogenically designed healthy ageing programmes, such as the AGES project in Japan (Misawa and Kondo, 2019), the SHAPE programme in Singapore (Seah et al., 2018), a health promotion intervention amongst ageing migrants (Arola et al., 2018) and finally an empowering self-management model on the self-efficacy and SOC in Iranian elderly (Hourzad et al., 2018). This is encouraging because research has moved from testing to implementation in practice.

\section{GRRs and SRRs for Older People}

Two important concepts in the salutogenic theory are generalized resistance resources (GRRs) and specific resistance resources (SRRs). Generalized resistance resources (GRRs) are those resources that help a person to avoid or to combat a wide variety of stressors (Antonovsky, 1979). GRRs arise from the cultural, social and environmental living conditions and early childhood upbringing and socialization experiences (see Chap. 7). GRRs can be found not only within people as resources bound to their person and capacity, but also within their immediate and distant environment and can be both material and non-material (Lindström and Eriksson, 2005). Examples of GRRs are genetic and constitutional qualities, knowledge, intelligence, ego-strength, control, social support, commitment, cultural stability and also material resources such as money. Importantly, it is not just that such resources are available, but that the individual has the capacity to recognize, use and reuse the resources for the intended purpose, which helps to increase health and wellbeing. GRRs are applicable in a wide variety of situations. SRRs on the other hand are particular resources, useful in specific situations. Or, as Mittelmark et al. put it, a GRR is a generality, an SRR is a particularity (Mittelmark et al., 2017, p. 75). In their words, ' $\ldots$ SRRs ... are optimized by societal action in which public health has a contributing role, for example, the provision of ... health and social and protective (welfare) services, and supportive social and physical environments'.

\section{The Community}

Many of the 'prerequisites' to strengthen GGRs, SRRs and SOC are provided by or mediated through the community. But what constitutes a community? Even though the concept is used often in health promotion literature, there is no general understanding of the concept. However, two broad lines can be distinguished, that is, definitions in terms of geographical area and definitions in terms of shared characteristics (Koelen and van den Ban, 2004, p. 136). For the sake of simplicity, here we mean groups of people living in a certain geographical area, often sharing a common culture, values and norms, and who are placed in a social structure according to relationships which the community has developed over a period of time (based on Nutbeam, 1998).

At the centre of the community is the house, which is considered to be the primary setting for ageing in place (Felix et al., 2015; Orrell et al., 2013; Oswald and Wahl, 2005; Sixsmith and Sixsmith, 1991). Older people spend on average $80 \%$ of their time inside the house (Oswald et al., 2006; Windle et al., 2006). Studies by, for example, Felix et al. (2015), Oswald et al. (2006), Percival (2002), Rowles (1983), Sixsmith 
(1986) and Smith (1994) show a variety of conditions that turn a house into a meaningful place in which to live. In the broader sense, 'home' refers to the constellation of both the built and social community within which the individual resides (Stones and Gullifer, 2016). The physical structure of the house functions as a stage for daily activities. Basic qualities of the house, like daylight, the level of thermal and sound insulation, and the ease of maintenance are valued for their physical comfort, as well as for providing feelings of privacy, safety, freedom and independence. A meaningful house enhances feelings of personal control, autonomy and responsibility, which seem to be pivotal to health development (Koelen and Lindström, 2005) and hence to healthy ageing. People who have a responsibility for day-to-day events, even seemingly small things such as watering plants, or caring for a little bird or dog, have more favourable psychological well-being and show higher health and activity patterns than people without such responsibilities (e.g. Rodin and Langer, 1977). In addition, the house provides a place for personal belongings, which are used to set priorities in life, to create a personal atmosphere and to keep memories of the past alive. As Rowles and Bernard (2013) argue, one's own home provides security, it holds memories and it provides the possibility to stay in proximity with friends, neighbours, kin and local services. As such, one's own home contributes to each of the SOC components: meaningfulness, comprehensibility and manageability.

The social dimension of the house is shaped through interaction with the surrounding community environment, which first of all includes the near social environment (family, friends, and neighbours). Social contacts are seen as an enrichment of life for all age groups: it is fun to do things together. It seems that, especially when people become older, social contacts become more and more important (Oswald and Wahl, 2005; Puts et al., 2007).

A key finding in a qualitative study by Felix et al. (2015), which focused on the experience of the house as a home, was that all participants mentioned the importance of the neighbourhood for feeling at home. Having contact with neighbours, the provision of help and care and the availability of facilities locally seem to be essential for people's sense of 'home'. Research shows that, irrespective of physical decline during older age, most older people prefer to continue living in their own homes amongst their own communities (Stones and Gullifer, 2016). Indeed, many aspects of the community environment are important for older people. This includes the social environment, which provides a feeling of belonging and social inclusion; features of the built environment, including services such as shops, restaurants, schools, churches and community centres, formal and informal health services and infrastructure and transportation; and features of the natural environment, such as availability of urban green space and recreation areas (Felix et al., 2015; Stephens et al., 2015). A study of Yu et al. (2019) showed that perceived neighbourhood environments were positively associated with sense of community and self-rated health. Especially 'transportation' and 'respect and social inclusion' were the physical and the social environmental domains most strongly associated with sense of community. Clearly, the physical and social environments interact. Spatial design of housing, proximity of shops, church and other services and infrastructure largely influence the mobility, self-reliance and social participation in the neighbourhood and larger community. A lack of facilities in each of these domains may negatively affect quality of life. Hence, the neighbourhood can provide important GRRs for older people. In their review study, Khoon-Kiat et al. (2013, p. 497) concluded that older people who have access to GRRs are more likely to have a strong SOC, relatively good health and quality of life.

\section{Ageing in the Community}

Important for healthy ageing is that people have the possibility to age in place. Ageing in place can be defined as 'the ability to live in one's own home and community safely, independently, and comfortably, regardless of age, income or ability level' (Centers for Disease Control \& Prevention, 2009, p. 1). It enables older people to not only maintain autonomy and independence, but also connection to social support, family and friends. Assisting people to age in place implies that older people receive adequate support whilst they continue to live and be involved in the community. Attention needs to be given to housing options, health and care services, transportation, recreational opportunities and facilities for social interaction and cultural engagement. Over the past decade, the concept of 'age-friendly communities' has emerged. According to the $\mathrm{WHO}$, 'in an age-friendly community, policies, services and structures related to the physical and social environment are designed to support and enable older people to "age actively", that is, to live in security, enjoy good health and continue to participate fully in society. Public and commercial settings and services are made accessible to accommodate varying levels of ability' (WHO, 2002). In line with this, in 2010 WHO established the Global Network for Age-friendly Cities and Communities (AFCC). The mission of the network is to stimulate and enable cities and communities around the world to become increasingly age-friendly. Currently, over 1000 cities and communities in 41 countries, covering over 240 million people worldwide, are connected to the network (WHO, n.d.) which shows the relevance that is assigned to facilitate healthy ageing. AFCC builds on the notion that the physical and social environment contribute to physical health, mental health and well-being (Menec and Brown, 2018), hence to quality of life. Menec et al. (2011) provided an interesting conceptualization of age-friendly communities (see Fig. 19.1).

According to the authors, age-friendly communities create connections between the older persons and the environ- 


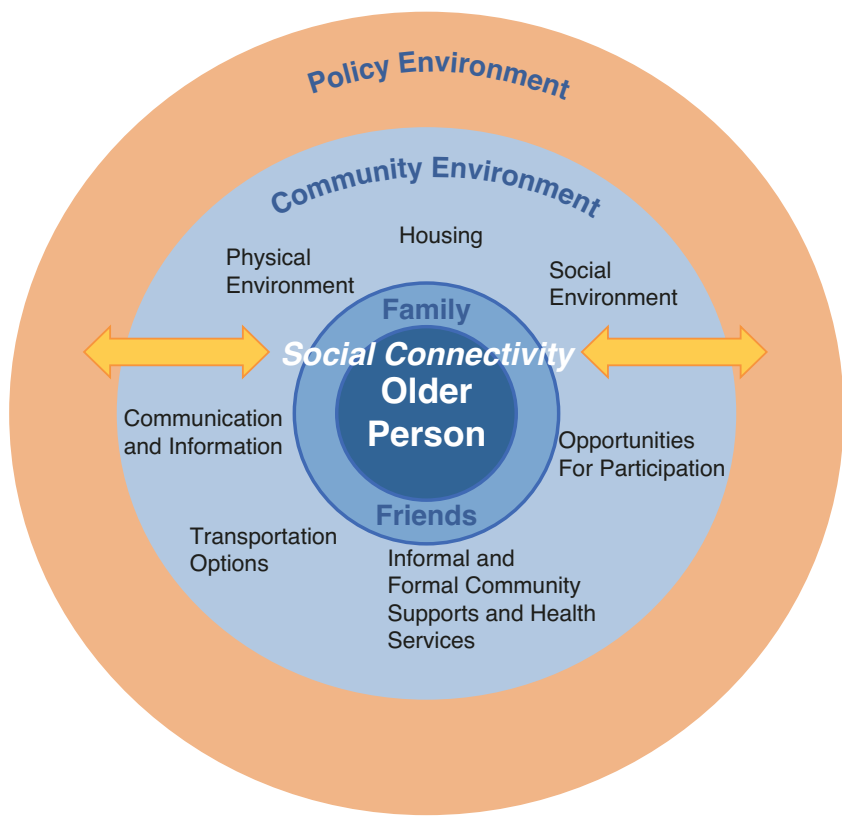

Fig. 19.1 Conceptualizing age-friendly communities . (Reprinted with permission from Cambridge University Press. Menec et al., 2011. This Figure cannot be reproduced, shared, altered or exploited commercially in any way without the permission of Cambridge University Press, as it is copyrighted material and therefore not subject to the allowances permitted by a CC licence)

ment in which they live and vice versa (p. 484). Without an extensive description of the seven identified community dimensions, we wish to emphasize the importance that is attached to conditions in both the physical and social environment contributing (or not) to healthy ageing. Housing is in fact a part of the physical environment but is considered in its own right. This relates to what we have mentioned before about housing and feelings of home. Also opportunities for participation are considered important. This includes social participation and employment, but also other forms of participation such as physical activity, spiritual activity and volunteer options.

From a life course perspective, perhaps an even more interesting concept is that of 'intergenerational communities'. In the age-friendly communities approach, the focus is foremost on how older people can be supported in the context of their environment. However, older people do not live in isolation but are part of the 'whole-life-cycle environment', which includes newborns, children, youth, young and older adults. Intergenerational communities address quality of life and physical and psychological needs for all age groups, with an additional consideration of how different generations interact and form relationships (Kaplan et al., 2016, p. 118). An intergenerational lens may also prevent communities to loose fit with its inhabitants. Communities are no static entities, but change over time, both in terms of population demography (e.g. from mainly young families to a mostly ageing population), the level of maintenance and quality of housing and the surroundings. In fact, communities with features which are important for older people might also be beneficial for children and young adults. For example, the quality of side-walks is important for both older people needing walking aids and young parents using a baby buggy. Moreover, intergenerational contacts are beneficial for all age groups, and, as pointed out before, healthy ageing is a lifelong process, evolving throughout the lifespan.

Intergenerational communities are age-friendly communities, creating connections between the older persons and the environment in which they live and vice versa. This very much relates to the SOC dimension of meaningfulness. The maintenance of social relationships and having the possibility to be physically and socially active is closely related to having a purpose in life (Takkinen and Ruoppila, 2001; Stones and Gullifer, 2016). It enables older people to recognize and use GRRs to strengthen one or more of the three dimensions of SOC - meaningfulness, manageability and comprehensibility - which in turn enables them to recognize, pick up and use SRRs as needed in specific encounters with stressors (see Chap. 8). The home and neighbourhood provide a basis for consistency (coherence) and GRRs, enhancing meaningfulness, comprehensibility and manageability. Intergenerational communities provide supportive environments for people whilst ageing. They provide resources for health in the social and physical environment which - combined with their personal resources - enable people to live their lives despite possible limitations. The model of intergenerational communities may provide a useful framework for future research and practice, towards the facilitation of independence, participation and well-being of older people.

\section{Discussion and Implications for Salutogenic Research}

Older people's perceptions of healthy ageing, that is, being independent, being connected, being able to use resources, being able to make one's own decisions (see the relation with the three dimensions of SOC), are related to the notion of ageing in place. Especially the availability of social contacts, the ability to engage in social interaction and the availability and accessibility of social and material resources (GRRs and SRRs) are important. The community, with home as a central place, offers many opportunities for maintaining or enhancing well-being and quality of life of older people.

Developing age-friendly, or preferably intergenerational communities, is more easily said than done. It requires input from a variety of disciplines, from the health, care and social sector, to architecture, city design and environmental planning. The fact that there is a difference in the perception of what constitutes healthy ageing and what is needed for ageing healthy by older people, professionals, researchers and policymakers emphasize the importance of active participation 
of older people in research and policy-making for healthy ageing, and also for environmental design. It can be expected that such differences in perceptions also exist between different age groups and between age groups and professionals. An intergenerational approach, hence, also requires input from the other age groups. Participation in decision-making and planning enhances feelings of control and empowerment, which, in turn, may contribute to a strong(er) SOC.

Societies are changing at a rapid pace, and ICTs are increasingly applied in all areas of society. The ability to use them is also increasingly essential for everyday life activities. The digitization of various activities in society can mean that new opportunities open up for older people to live an active life but can also be marginalizing for people who do not master the technology. Therefore, it becomes important when designing technological solutions for older people to take this notion into account. Another new innovation is that of artificial intelligence (AI), commonly known as robots with built-in human characteristics such as speech. So far, research of what the consequences of AI are for elderly is still scarce.

\section{References}

Aldwin, C. M., Spiro, A., III, \& Park, C. L. (2006). Health, behaviour, and optimal aging: A life span developmental perspective. In J. E. Birren \& K. W. Schaie (Eds.), Handbook of the psychology of aging. Elsevier Academic Press.

Antonovsky, A. (1979). Health, stress and coping. Jossey-Bass.

Antonovsky, A. (1985). The life cycle, mental health and the sense of coherence. The Israel Journal of Psychiatry and Related Sciences, 22(4), 273-280.

Antonovsky, A. (1987). Unraveling the mystery of health. How people manage stress and stay well. Jossey-Bass.

Antonovsky, A. (1993). The salutogenic approach to aging. A lecture held in Berkeley, 21 January 1993. Retrieved 24 Feb 2015, from http://www.angelfire.com/ok/soc/a-berkeley.html.

Arola, L. A., Barenfels, E., Dahlin-Ivanoff, S., \& Häggblom-Kronlof, G. (2018). Distribution and evaluation of sense of coherence among older immigrants before and after a health promotion intervention results from the RCT study promoting aging migrants' capability. Clinical Intervention and Aging, 13, 2317-2328.

Beard, J. R., Officer, A., Araujo de Carvalho, I., Sadana, R., Pot, A. M., Michel, J.-P., Lloyd-Sherlock, P., Epping-Jordan, J. E., Peeters, G. M. E. E., Mahanani, W. R., Thiygarajan, J. A., \& Chatterji, S. (2016). The world report on ageing and health: A policy framework for healthy ageing. The Lancet, 387(10033), 2145-2154.

Billings, J., \& Hashem, F. (2010). Mental health and well-being in older people-making it happen. Paper presented at the EU conference "Salutogenesis and the promotion of positive mental health in older people", Madrid, 19-20 April 2010.

Boeckxstaens, P., Vaes, B., De Sutter, A., Aujoulat, I., van Pottelbergb, G., Matbei, C., \& Degryse, J. M. (2016). A high sense of coherence as protection against adverse health outcomes in patients aged 80 years and older. Annals of Family Medicine, 14(4), 337-343.

Cattan, M. (Ed.). (2009). Mental health and well-being in later life. Open University Press/McGraw-Hill.
Centers for Disease Control and Prevention. (2009). Healthy places terminology. Retrieved 27 May 2015, from http://www.cdc.gov/ healthyplaces/terminology.htm.

Cooper, R., Hardy, R., Sayers, A., \& Kuh, D. (2014). A life course approach to physical capability. In D. Kuh, R. Cooper, R. Hardy, M. Richards, \& Y. Ben-Schlomo (Eds.), A life course approach to healthy ageing (1st ed., pp. 16-31). Oxford University Press.

Dezutter, J., Wiesmann, U., Apers, S., \& Luyckx, K. (2013). Sense of coherence, depressive feelings and life satisfaction in older persons: A closer look at the role of integrity and despair. Aging \& Mental Health, 17(7), 839-843.

Drageset, J., Espehaug, D., Halberg, I. R., \& Natvig, G. K. (2014). Sense of coherence among cognitively intact nursing home residents-A five-year longitudinal study. Aging \& Mental Health, 18(7), 889-896.

Drageset, J., \& Haugan, G. (2015). Psychometric properties of the orientation to life questionnaire in nursing home residents. Scandinavian Journal of Caring Sciences. https://doi.org/10.1111/scs.12271

Dykstra, P. A. (2009). Older adult loneliness: Myths and realities. European Journal of Ageing, 6, 91-100.

Erikson, E. H., \& Erikson, J. (1998). The life cycle completed. W.W. Norton.

Eriksson, M. (2017). The sense of coherence in the salutogenic model of health. In M. B. Mittelmark, S. Sagy, M. Eriksson, G. F. Bauer, J. M. Pelikan, B. Lindström, \& G. A. Espnes (Eds.), The Handbook of Salutogenesis.

Eriksson, M., \& Lindström, B. (2005). Validity of Antonovsky's sense of coherence scale-A systematic review. Journal of Epidemiology \& Community Health, 59(6), 460-466.

Eriksson, M., \& Lindström, B. (2006). Antonovsky's sense of coherence scale and the relation with health: A systematic review. Journal of Epidemiology \& Community Health, 60(5), 376-381.

Eriksson, M., \& Lindström, B. (2011). Life is more than survival: Exploring links between Antonovsky's salutogenic theory and the concept of resilience. In K. M. Gow \& M. J. Celinski (Eds.), Wayfinding through life's challenges: Coping and survival. Nova.

Eurostat. (2013). Statistics explained archive. In Vol. 2-Social statistics, December 2012. Publications Office of the European Union.

Eurostat (2018). Population structure and ageing. Retrieved 6 Nov 2019 from https://ec.europa.eu/eurostat/statistics-explained/index. php.

Feldt, T., Leskinen, E., Koskenvuo, M., Suominen, S., Vahtera, J., \& Kivimäki, M. (2011). Development of sense of coherence in adulthood: A person-centered approach. The Population-Based HeSSup Cohort Study. Quality of Life Research, 20, 69-79.

Feldt, T., Lintula, H., Suominen, S., Koskenvuo, M., Vahtera, J., \& Kivimäki, M. (2007). Structural validity and temporal stability of the 13-item sense of coherence scale: Prospective evidence from the population-based HeSSup study. Quality of Life Research, 16, 483-493.

Felix, E., de Haan, H., Vaandrager, L., \& Koelen, M. (2015). Beyond thresholds: Exploring the meaning of home for older people in the Netherlands. Journal of Housing for the Elderly, 29, 329-347.

Forsman, A. K., \& Nordmyr, J. (2015). Psychosocial links between Internet use and mental health in later life: A systematic review of quantitative and qualitative evidence. Journal of Applied Gerontology, 1-48. https://doi.org/10.1177/0733464815595509

Forte, D. (2009). Relationships. In M. Cattan (Ed.), Mental health and well-being in later life (pp. 84-111). Open University Press/ McGraw-Hill.

Guo, L.-N., Liu, Y.-J., McCallum, J., Söderhamn, U., Ding, X.-F., Yv, S.-Y., Zhu, Y.-R., \& Guo, Y.-R. (2018). Perceived stress and depression amongst older stroke patients: Sense of coherence as a mediator? Archives of Gerontology and Geriatrics, 79, 164-170.

Hanson-Kyle, L. (2005). A concept analyses of healthy aging. Nursing Forum, 40(2), 45-57. 
Hicks, M. M., \& Conner, N. E. (2014). Resilient ageing: A concept analysis. Journal of Advanced Nursing, 70(4), 744-755. https://doi. org/10.1111/jan.12226

Hornby-Turner, Y. C., Peel, N. M., \& Hubbard, R. E. (2017). Health assets in older age: A systematic review. BMJ Open, 7, e013226. https://doi.org/10.1136/bmjopen-2016-013226

Hourzad, A., Pouladi, S., Ostovar, A., \& Ravanipour, M. (2018). The effects of an empowering self-management model on self-efficacy and sense of coherence among retired elderly with chronic diseases: A randomized controlled trial. Clinical Interventions in Aging, 13, 2215-2224.

Huber, M., Knottnerus, J. A., Green, L., van der Horst, H., Jadad, A. R., Kromhout, D., Leonard, B., Lorig, K., Loureiro, M. I., van der Meer, J. W., Schnabel, P., Smith, R., van Weel, C., \& Smid, H. (2011). How should we define health? British Medical Journal, 343, d4163. https://doi.org/10.1136/bmj.d4163

Hubley, J., \& Copeman, J. (2008). Practical health promotion. Polity Press.

Jeste, D. V., Depp, C. A., \& Vahia, I. V. (2010). Successful cognitive and emotional aging. World Psychiatry, 9(2), 78-84.

Kaplan, M., Sanchez, M., \& Hoffman, J. (2016). Intergenerational pathways to a sustainable society. In Intergenerational strategies for sustaining strong communities (pp. 109-139). Springer.

Kennaugh, R. (2016). "It's not how old we are; it's how we are old": A salutogenic approach to how older Australian women experience ageing and respond to life stressors. University of Newcastle, Australia, doctoral thesis.

Khoon-Kiat, T., Vehvilainen-Julkunen, K., \& Wai-Chi-Chan, S. (2013). Integrative review: Salutogenesis and health in older people over 65 years old. Journal of Advanced Nursing, 70(3), 497-510.

Kingston, A., Davies, K., Collerton, J., Robinson, L., Duncan, R., Kirkwood, T. B. L., \& Jagger, C. (2015). The enduring effect of education-socioeconomic differences in disability trajectories from age 85 years in the Newcastle 85+ Study. Archives of Gerontology and Geriatrics, 60, 405-411.

Koelen, M. A. (2011). Health and society: New kid on the block. Wageningen University.

Koelen, M. A., \& Lindström, B. (2005). Making healthy choices easy choices: The role of empowerment. European Journal of Clinical Nutrition, 59(Suppl. 1), 10-16.

Koelen, M. A., \& van den Ban, A. W. (2004). Health education and health promotion. Wageningen.

Krok, D. (2015). Sense of coherence mediates the relationship between the religious meaning system and coping styles in Polish older adults. Aging \& Mental Health, 19, 1-8.

Kuh, D. (2019). A life course approach to healthy ageing. In J. P. Michel (Ed.), Prevention of chronic diseases and agerelated disability. Practical issues in Geriatrics. https://doi. org/10.1007/978-3-319-96529-1_1

Kuh, D., \& Ben Shlomo, Y. (2004). A life course approach to chronic disease epidemiology. Oxford University Press.

Lezwijn, J., Vaandrager, L., Naaldenberg, J., Wagemakers, A., Koelen, M. A., \& van Woerkum, C. M. J. (2011). Healthy ageing in a salutogenic way: Building the HP 2.0 framework. Health \& Social Care in the Community, 19(1), 43-51.

Lim, S. (2020). Strategies to improve continuity maintenance for people with dementia: A rapid realist review. Public Health, 181, 46-52.

Lindström, B., \& Eriksson, M. (2005). Salutogenesis. Journal of Epidemiology and Community Health, 59(6), 440-442.

Lópes, J., Camilli, C., \& Noriega, C. (2014). Posttraumatic growth in widowed and non-widowed older adults: Religiosity and sense of coherence. Journal of Religion and Health, 53(6). https://doi. org/10.1007/s10943-014-9876-5

Lövheim, H., Graneheim, U. H., Jonsen, E., Starndberg, G., \& Lundman, B. (2012). Changes in sense of coherence in old age-a 5-year follow-up of the Umeå 85+ study. Scandinavian Journal of Caring Science, 27(1), 13-19.
Marcoen, A., Coleman, P., \& O'Hanlon, A. (2007). Psychological ageing. In J. Bond, S. Peace, F. Dittman-Kohli, \& G. Westerhof (Eds.), Ageing in society (pp. 38-67). Sage.

Menec, V. H., Means, R., Jeating, N., Parkhurst, G., \& Eales, J. (2011). Conceptualizing age-friendly communities. Canadian Journal on Aging, 30(3), 479-493.

Menec, V., \& Brown, C. (2018). Facilitators and barriers to becoming age-friendly: A review. Journal of Aging \& Social Policy. https:// doi.org/10.1080/08959420.20181528116

Mittelmark, M. B., Bull, T., Daniel, M., \& Urke, H. (2017). Specific resistance resources in the salutogenic model of health. In M. B. Mittlemark, S. Sagy, M. Eriksson, G. F. Bauer, J. M. Pelikan, B. Lindström, \& G. A. Espnes (Eds.), The handbook of salutogenesis. Springer. Open access. https://doi. org/10.1007/978-3-319-04600-6

Misawa, J., \& Kondo, K. (2019). Social factors relating to depression among older people in Japan: Analysis of longitudinal panel data from the AGES project. Aging \& Mental Health, 23(10), 1423-1432.

Murayama, Y., Ohba, H., Yasunaga, H., Nonaka, K., Takeuchi, R., Nishj, M., Sakuma, N., Uchida, H., Shinkai, S., \& Fujiwara, Y. (2014). The effect of intergenerational programs on the mental health of elderly adults. Aging \& Mental Health. https://doi.org/10 $.1080 / 136077863.136072014 .136933309$

Naaldenberg, J., Vaandrager, L., Koelen, M. A., \& Leeuwis, C. (2011). Ageing populations' everyday life perspectives on healthy aging: New insights for policy and strategies at the local level. Applied Gerontology. https://doi.org/10.1177/0733464810397703

Nilsson, K., Leppert, J., Simonsson, B., \& Starrin, B. (2010). Sense of coherence (SOC) and psychological well-being (GHQ): Improvement with age. Journal of Epidemiology and Community Health, 64(4), 347-352.

Nutbeam, D. (1998). Health promotion glossary. WHO/HPR/HEP/98.1. World Health Organisation.

Nyqvist, F., Cattan, M., Andersson, L., Forsman, A. K., \& Gustafson, Y. (2013). Social capital and loneliness among the very old living at home and in institutional settings: A comparative study. Journal of Aging and Health. https://doi.org/10.1177/0898264313497508

Orrell, A., McKee, K., Torrington, J., Barnes, S., Darton, R., Netten, A., et al. (2013). The relationship between building design and residents' quality of life in extra care housing schemes. Health \& Place, 21, 52-64.

Oswald, F., \& Wahl, H. W. (2005). Dimensions of the meaning of home in later life. In G. D. Rowles \& H. Chaudhury (Eds.), Home and identity in late life: International perspectives (pp. 21-45). Springer.

Oswald, F., Wahl, H. W., Naumann, D., Mollenkopf, H., \& Hieber, A. (2006). The role of the home environment in middle and late adulthood. In H. W. Wahl, H. Brenner, H. Mollenkopf, D. Rothenbacher, \& C. Rott (Eds.), The many faces of health, competence and wellbeing in old age (pp. 7-24). Springer.

Percival, J. (2002). Domestic spaces: Uses and meanings in the daily lives of older people. Aging and Society, 22, 729-749.

Phillipson, C., \& Baars, J. (2007). Social theory and social ageing. In J. Bond, S. Peace, F. Dittman-Kohli, \& G. Westerhof (Eds.), Ageing in society (pp. 68-84). Sage.

Potier, F. (2018). A high sense of coherence protects from the burden of caregiving in older spousal caregivers. Archives of Gerontology and Geriatrics, 75, 76-82.

Puts, M. T. E., Shekary, N., Widdershoven, G., Helders, P. J., Lips, P., \& Deeg, D. J. H. (2007). What does quality of life mean to older frail and non-frail community-dwelling adults in the Netherlands? Quality of Life Research, 16, 263-277.

Rodin, J., \& Langer, E. J. (1977). Long-term effects of a control-relevant intervention with the institutionalized aged. Journal of Personality and Social Psychology, 35(12), 897-902. 
Rowles, G. D. (1983). Place and personal identity in old age: Observations from Appalachia. Journal of Environmental Psychology, 3, 299-313.

Rowles, G. D. R., \& Bernard, M. B. (2013). The meaning and significance of place in old age. In G. D. R. Rowles \& M. B. Bernard (Eds.), Environmental gerontology: Making meaningful places in old age (pp. 2-24). Springer.

Sadana, R., \& Michel, J.-P. (2019). Healthy ageing: What is it and how to describe it? In J.-P. Michel (Ed.), Prevention of chronic diseases and age-related disability. Practical Issues in Geriatrics. https://doi. org/10.1007/978-3-319-96529-1_2

Saevareid, H. I., Thygesen, E., Nygaard, H. A., \& Lindstrom, T. C. (2007). Does sense of coherence affect the relationship between selfrated health and health status in a sample of community-dwelling frail elderly people? Aging \& Mental Health, 11(6), 658-667.

Seah, B., Espnes, G. A., Ang, E. N. K., Kowitlawakul, Y., \& Wang, W. (2020). Achieving healthy ageing through the perspective of sense of coherence among senior-only households: a qualitative study. Aging \& Mental Health, 1725805. https://doi.org/10.1080/13607863.2020

Seah, B., Kowitlawakul, Y., Chokkanathan, S., Fong, J. J. Y., Espnes, G. A., Ang, E., \& Wang, W. (2018). Salutogenic Healthy Ageing Programme Embracement (SHAPE) for senior-only households: A study protocol. Journal of Advanced Nursing, 74, 946-956.

Sherman, H., Forsberg, C., Karp, A., \& Törnkvist, L. (2012). The 75-year-old persons' self-reported health conditions: A knowledge base in the field of preventive home visits. Journal of Clinical Nursing, 21(21-22), 3170-3182.

Sixsmith, J. (1986). The meaning of home: An exploratory study of environmental experience. Journal of Environmental Psychology, 6, 281-298.

Sixsmith, A. J., \& Sixsmith, J. A. (1991). Transitions in home experience in later life. Journal of Architectural and Planning Research, 8, 181-191.

Smith, S. G. (1994). The essential qualities of a home. Journal of Environmental Psychology, 14, 31-46.

Staehelin, H. B. (2005). Promoting health and wellbeing in later life. In M. L. Johnson, V. L. Bengtson, P. G. Coleman, \& T. B. L. Kirkwood (Eds.), The Cambridge book of age and ageing (pp. 165-177). Cambridge University Press.

Stensletten, K., Bravik, F., Espehaug, B., \& Drageset, J. (2014). Burden of care, social support, and sense of coherence in elderly caregivers living with individuals with symptoms of dementia. Dementia. https://doi.org/10.1177/1471301214563319
Stephens, C., Breheny, M., \& Mansvelt, J. (2015). Healthy ageing from the perspective of older people: A capability approach to resilience. Psychology and Health, 30(6), 715-731. https://doi.org/10.1080/08 870446.2014 .904862

Stones, D., \& Gullifer, J. (2016). 'At home it's just so much easier to be yourself': Older adults' perceptions of ageing in place. Ageing \& Society, 36, 449-482.

Takkinen, S., \& Ruoppila, I. (2001). Meaning in life in three samples of elderly persons with high cognitive functioning. International Journal of Human Development, 53(1), 51-73.

Tan, K.-K., Vehviläinen-Julkunen, K., \& Chan, S. W.-C. (2013). Integrative review: Salutogenesis and health in older people over 65 years old. Journal of Advanced Nursing, 70(3), 497-510.

Walsh, S. (2014). Salutogenesis 2.0: An examination of healthy ageingin-place using a qualitative application of the Sense of Coherence. Doctoral thesis. National University of Ireland Maynooth.

Westendorp, R. G., \& Kirkwood, T. B. (2007). The biology of ageing. In J. Bond, S. Peace, F. Dittman-Kohli, \& G. Westerhof (Eds.), Ageing in society (pp. 15-37). Sage.

WHO. (2002). Global age friendly cities. Retrieved 3 March 2015, from www.who.int/ageing/projects/age_friendly_cities/en/.

WHO. (2015). Ageing and lifecourse. Retrieved 6 Nov 2019 from: https://www.who.int/ageing/healthy-ageing/en/.

WHO. (n.d.). About the Global Network for Age-friendly Cities and Communities. Retrieved 3 March 2020 from: https://extranet.who. int/agefriendlyworld/who-network/.

Wiesmann, U., Dezutter, J., \& Hannich, H. J. (2014). Sense of coherence and pain experience in older age. International Psychogeriatrics, 26(1), 123-133.

Wiesmann, U., \& Hannich, H. J. (2019). A salutogenic inquiry into positive aging - a longitudinal analysis. Aging \& Mental Health, 23(11), 1562-1568.

Windle, G. S., Burholt, V., \& Edwards, R. T. (2006). Housing related difficulties, housing tenure and variations in health status: Evidence from older people in Wales. Health \& Place, 12, 267-278.

Young, Y., Frick, K. D., \& Phelan, E. A. (2009). Can successful ageing and chronic illness coexist in the same individual? A multidimensional concept of successful aging. Journal of the American Medical Directors Association, 10(2), 87-92.

Yu, R., Wong, M., \& Woo, J. (2019). Perceptions of neighborhood environment, sense of community, and self-rated health: an age-friendly city project in Hong Kong. Journal of Urban Health, 96, 276-288.

Open Access This chapter is licensed under the terms of the Creative Commons Attribution 4.0 International License (http://creativecommons. org/licenses/by/4.0/), which permits use, sharing, adaptation, distribution and reproduction in any medium or format, as long as you give appropriate credit to the original author(s) and the source, provide a link to the Creative Commons license and indicate if changes were made.

The images or other third party material in this chapter are included in the chapter's Creative Commons license, unless indicated otherwise in a credit line to the material. If material is not included in the chapter's Creative Commons license and your intended use is not permitted by statutory regulation or exceeds the permitted use, you will need to obtain permission directly from the copyright holder. 